\title{
Evaluation of the anesthetic effects of xylazine-ketamine, xylazine-tiletamine-zolazepam and tiletamine-zolazepam using clinical and laboratory parameters in rabbits
}

\author{
ABDULLAH KARASU, NURI ALTUG*, LOGMAN ASLAN, \\ BAHTIYAR BAKIR ${ }^{* *}$, NAZMI YUKSEK***
}

\begin{abstract}
Department of Surgery, Faculty of Veterinary Medicine, University of Van Yuzuncu Yil, Van, Turkey
*Department of Internal Medicine, Faculty of Veterinary Medicine, University of Namık Kemal, Tekirdağ, Turkey

**Health Services Vocational School, University of Gazi, Ankara, Turkey

${ }^{* * *}$ Department of Internal Medicine, Faculty of Veterinary Medicine, University of Van Yuzuncu Yil, Van, Turkey
\end{abstract}

Karasu A., Altug N., Aslan L., Bakir B., Yuksek N.

Evaluation of the anesthetic effects of xylazine-ketamine, xylazine-tiletamine-zolazepam and tiletamine-zolazepam using clinical and laboratory parameters in rabbits

\section{Summary}

The aim of this study was to evaluate the anesthetic effects of xylazine-ketamine (XK), xylazine-tiletaminezolazepam (XTZ) and tiletamine-zolazepam (TZ) using hematological and biochemical parameters in rabbits. A total of 18 rabbits were divided into three equal treatment groups $(n=6)$. The rabbits in the XK, XTZ, and TZ groups were administered xylazine $(5 \mathrm{mg} / \mathrm{kg})$ and ketamine $(50 \mathrm{mg} / \mathrm{kg})$, xylazine $(5 \mathrm{mg} / \mathrm{kg})$ and $\mathrm{TZ}$ $(15 \mathrm{mg} / \mathrm{kg})$, and TZ $(15 \mathrm{mg} / \mathrm{kg})$, respectively, via the intramuscular route. Following the injection, their reflexes were tested every 5 minutes. Heart rate, respiratory rate, and body temperature were determined before the injection ( $0 \mathrm{~min})$ and at 5, 15, 30, 45, 60, 75, 90, and $120 \mathrm{~min}$ after injecting the anesthetic combinations. Furthermore, hematological and biochemical (alanine transaminase [ALT], aspartate transaminase [AST], alkaline phosphatase [ALP], bilirubin, blood urea nitrogen [BUN], and urea) analyses were also performed before, during, and after anesthesia administration. The duration of anesthesia and loss of reflexes were significantly longer in the XTZ group than in the other groups. However, in the TZ group, reflexes were remained. Respiratory rate and body temperature decreased in all the groups. Moreover, heart rate reduced only in the XK and XTZ groups, and the hematological parameters of all groups were comparable. Serum AST and ALP levels increased in the XTZ group compared to that in the XK and TZ groups, respectively. However, these increases were within the reference limits. The post-anesthesia serum BUN and urea levels significantly increased in the XTZ group $(p<0.05)$ compared to that in the other groups. Thus, although the XTZ combination provided satisfactory anesthetic effect in rabbits, it may be nephrotoxic. Therefore, its use for anesthesia induction in invasive renal procedures and experimental nephrotoxicity studies is not advisable.

Keywords: xylazine, ketamine, tiletamine-zolazepam, anesthesia, hematology, biochemistry, rabbit

Rabbits are common companion animals and are widely used in experimental surgeries and biomedical research $(3,17)$. Moreover, they are the third most commonly anaesthetized pet animal in England (13). However, safe anesthesia of adequate depth and duration remains challenging in rabbits. These animals have strong reflexes that are difficult to suppress during general anesthesia (23). The anesthesia-related mortality rate is significantly higher in rabbits $(1.39 \%)$ than in $\operatorname{dogs}(0.17 \%)$ and cats $(0.24 \%)(3)$.
Many different injectable anesthetic drugs are used in rabbit anesthesia (13). Ketamine and xylazine are widely used drugs in rabbit anesthesia (25). Ketamine, a dissociative anesthetic, produces a state of cataleptic sedation and is usually administered in combination with xylazine or diazepam for inducing surgical anesthesia in rabbits. Xylazine produces sedation; however, it appears to exert a mild analgesic effect in rabbits (25). Tiletamine and zolazepam have dissociative anesthetic and tranquilizing properties, respectively. 
Tiletamine does not relax the muscles or affect the cranial nerve and spinal reflexes; however, the addition of zolazepam results in muscle relaxation. This combination is commonly used as part of the anesthetic management of domestic animals (19). Xylazine has been combined with tiletamine-zolazepam (TZ) to enhance its anesthetic and analgesic effects (25). The effects of anesthetics on cardiovascular and respiratory functioning have been extensively studied. However, limited information is available regarding the effects of anesthetics on the biochemical parameters of rabbits (10).

Effects of xylazine-ketamine (XK) on the liver and kidney (11) and that of xylazine-TZ (XTZ) and TZ on the kidneys $(2,25)$ of rabbits have been studied. However, to our knowledge, no study has compared the effects of XK, XTZ, and TZ on the anesthetic, hematological, liver, and renal parameters. Thus, we aimed to investigate these effects in rabbits that have an important place in experimental animals. The study objectives included the evaluation of the anesthetic effects of XK, XTZ, and TZ together using hematological and some biochemical parameters in rabbits.

\section{Material and methods}

Animals. Eighteen clinically healthy, local-breed, adult male rabbits weighing $2.20-2.85 \mathrm{~kg}$ were used. The animals were maintained in individual cages for at least 14 days before the experiments for acclimatization where they were fed commercial pellet food (Purina ${ }^{\circledR}$ ) and fresh water ad libitum. Food, but not water, was withheld for at least $12 \mathrm{~h}$ before the experiments. Experiments were performed during the light phase of the cycle (between 09:00 and 12:00 hours). The study was conducted after the study protocol was approved by the ethical committee of the Faculty of Veterinary Medicine, University of Yuzuncu Yil.

Experimental design. The rabbits were randomly assigned to either of the following three treatment groups ( $\mathrm{n}=6$ per group): XK, XTZ, and TZ groups. In the relevant groups, xylazine (Rompun ${ }^{\circledR}$, Bayer), ketamine (Ketamidor $^{\circledR}$, Richterpharma), and TZ (Zoletil ${ }^{\circledR}$, İ.E. Ulugay) were administered intramuscularly at doses of $5 \mathrm{mg} / \mathrm{kg}, 50 \mathrm{mg} /$ $\mathrm{kg}$, and $15 \mathrm{mg} / \mathrm{kg}$, respectively.

Anesthesia evaluation. Following the injection, the anesthesia depth was monitored based on the pedal withdrawal, ear pinch, and righting reflexes every 5 minutes. Induction time was determined as the time between the injection and the loss of righting reflex. Ear pinch reflex was assessed as a reaction to the pinching of the pinna with the thumb and the index finger. The pedal withdrawal reflex was evaluated as the withdrawal of the pelvic limb in response to pinching one digit with the thumb and the index finger. Recovery from anesthesia was evaluated as the ability of the animal to regain the righting reflex.

Cardiorespiratory rate and body temperature detection. row at $\mathrm{p}<0.001$
Heart rate, respiratory rate, and body temperature were monitored before the injection ( $0 \mathrm{~min})$ and at $5,15,30,45$, $60,75,90$, and $120 \mathrm{~min}$ after the injection of the anesthetic. The heart rate was determined using a stethoscope placed at the lower left lateral thoracic wall; the respiratory rate was visually counted, and body temperature was measured using a digital rectal thermometer.

Hematological analyses. Blood samples were collected in ethylenediaminetetraacetic acid tubes from the central ear artery using 21 -gauge needles just before administering the injection $(0 \mathrm{~min})$, and at 60 and $120 \mathrm{~min}$ after injection. Complete blood counts were assessed immediately after blood collection using a hematology analyzer (QBC vetautoreader $^{\mathbb{B}}-$ IDEXX). $^{2}$

Biochemical analyses. Blood samples were drawn from the central ear artery using 21 -gauge needles before injection ( $0 \mathrm{~min}$ ) and at $60 \mathrm{~min}$ and 1,3 , and 5 days after injection for biochemical analyses (alkaline phosphatase [ALP], alanine transaminase [ALT], aspartate transaminase [AST], bilirubin, blood urea nitrogen [BUN], and urea). Blood samples were placed in plain tubes and allowed to coagulate. They were then centrifuged (Rotofix $32 \mathrm{Hettich}^{\circledR}$ ) at $1200 \times \mathrm{g}$ and $4^{\circ} \mathrm{C}$ for 20 minute, and the serum was separated and stored at $-20^{\circ} \mathrm{C}$ until biochemical analyses. Serum ALP, ALT, AST, bilirubin, BUN, and urea were analyzed using a commercially available assay kit (ALP, ALT, AST, bilirubin, BUN and urea) with a spectrophotometer (Photometer $5010^{\circledR}$-Boehringer Mannheim).

Statistical analyses. Among the different groups, each parameter was compared using independent-samples t test. Within the same group, the changes in the value of each parameter after the anesthetic injection were compared using paired-samples $t$ test. For all statistical comparisons, differences were considered significant when $p$ value was $<0.05$. The calculations were performed utilizing SPSS software. All values are presented as means \pm standard deviations (SD).

\section{Results and discussion}

The data regarding anesthesia induction are presented in Tab. 1. There was no significant difference between the groups with regard to the induction time $(\mathrm{p}>0.05)(\mathrm{Tab} .1)$. The ear pinch and pedal withdrawal reflexes were lost in the XK and XTZ groups, but not in the TZ group during anesthesia induction. The duration of loss of the ear pinch and withdrawal reflex was significantly greater in the XTZ group than in the XK group $(\mathrm{p}<0.001)$. The recovery time was longest in the XTZ group $(115.50 \pm 9.26 \mathrm{~min})$, followed by that

Tab. 1. Induction time, duration of loss of ear pinch reflex, duration of loss of pedal withdrawal reflex and recovery time in the xylazine-ketamine (XK), xylazine-tiletamine-zolazepam (XTZ), and tiletamine-zolazepam (TZ) groups $(\overline{\mathrm{x}} \pm \mathrm{SD}, \mathrm{n}=6)$

\begin{tabular}{|l|c|c|c|}
\hline \multicolumn{1}{|c|}{ Criteria } & XK & XTZ & TZ \\
\hline Induction time (min) & $3.03 \pm 1.05$ & $2.71 \pm 0.81$ & $2.96 \pm 1.36$ \\
\hline Duration of loss of ear pinch reflex $(\min )$ & $27.50 \pm 4.43^{\mathrm{a}}$ & $62.50 \pm 4.78^{\mathrm{b}}$ & $0.00 \pm 0.00^{\mathrm{c}}$ \\
\hline Duration of loss of pedal withdrawal reflex $(\mathrm{min})$ & $25.80 \pm 3.50^{\mathrm{a}}$ & $58.34 \pm 6.00^{\mathrm{b}}$ & $0.00 \pm 0.00^{\mathrm{c}}$ \\
\hline Recovery time $(\mathrm{min})$ & $80.35 \pm 10.41^{\mathrm{a}}$ & $115.50 \pm 9.26^{\mathrm{b}}$ & $61.15 \pm 6.95^{\mathrm{ac}}$ \\
\hline
\end{tabular}

Explanation: $\mathrm{a}, \mathrm{b}, \mathrm{c}-$ means with different superscript letters differ significantly in the same 
Tab. 2. Heart rate and respiratory rate at various times in the xylazine-ketamine (XK), xylazine-tiletamine-zolazepam (XTZ), and tiletamine-zolazepam (TZ) groups $(\bar{x} \pm S D, n=6)$

\begin{tabular}{|c|c|c|c|c|c|c|}
\hline \multirow{2}{*}{ Time $(\mathrm{min})$} & \multicolumn{3}{|c|}{ Heart rate (beats per minute) } & \multicolumn{3}{c|}{ Respiratory rate (breaths per minute) } \\
& XK & XTZ & TZ & XK & XTZ & TZ \\
\hline 0 & $251.25 \pm 7.73$ & $222.00 \pm 11.48$ & $235.00 \pm 8.66$ & $121.50 \pm 11.59$ & $114.75 \pm 4.50$ & $142.25 \pm 7.42$ \\
5 & $230.00 \pm 12.41$ & $216.25 \pm 14.63$ & $230.00 \pm 10.00$ & $64.75 \pm 5.40^{*}$ & $54.50 \pm 4.11^{* * *}$ & $132.50 \pm 8.29$ \\
15 & $206.25 \pm 6.25^{* *}$ & $181.25 \pm 3.14$ & $230.75 \pm 8.74$ & $63.00 \pm 2.38^{*}$ & $48.75 \pm 3.15^{* * *}$ & $112.50 \pm 4.78^{*}$ \\
30 & $167.50 \pm 10.89^{*}$ & $177.50 \pm 3.22^{*}$ & $231.25 \pm 7.18$ & $57.00 \pm 1.22^{* *}$ & $54.50 \pm 2.36^{* * *}$ & $102.50 \pm 3.22^{*}$ \\
45 & $182.50 \pm 8.53^{* *}$ & $177.50 \pm 1.50^{*}$ & $232.50 \pm 10.90$ & $68.75 \pm 3.14^{*}$ & $60.25 \pm 1.93^{* * *}$ & $97.50 \pm 3.47^{*}$ \\
60 & $167.50 \pm 7.60^{* *}$ & $166.75 \pm 5.34^{*}$ & $235.75 \pm 9.47$ & $65.75 \pm 3.94^{* * *}$ & $54.50 \pm 1.25^{* * *}$ & $93.75 \pm 2.39^{*}$ \\
75 & $161.25 \pm 7.45^{* *}$ & $159.75 \pm 4.13^{*}$ & $232.50 \pm 11.08$ & $78.00 \pm 7.39^{*}$ & $48.00 \pm 2.7^{* * *}$ & $104.75 \pm 2.10$ \\
90 & $168.00 \pm 7.11^{*}$ & $159.25 \pm 4.88^{* *}$ & $232.50 \pm 11.86$ & $78.75 \pm 5.15^{*}$ & $48.00 \pm 2.70^{* * *}$ & $112.50 \pm 2.75$ \\
120 & $178.75 \pm 2.42^{*}$ & $158.75 \pm 8.75^{* *}$ & $237.50 \pm 6.29$ & $73.75 \pm 4.97^{*}$ & $58.75 \pm 3.49^{* * *}$ & $117.00 \pm 3.50$ \\
\hline
\end{tabular}

Explanation: statistical significance at each time point according to baseline values in all groups: ${ }^{*} \mathrm{p}<0.05 ; * * \mathrm{p}<0.01 ; * * * \mathrm{p}<0.001$

in the XK $(80.35 \pm 10.41 \mathrm{~min})$ and $\mathrm{TZ}(61.15 \pm 6.95$ min) groups. Furthermore, these reflexes and recovery times were significantly different among the groups $(\mathrm{p}<0.001)$.

The heart rate and respiratory rate of rabbits are shown in Tab. 2. Compared to the baseline values, the heart rate decreased at $15-120 \mathrm{~min}$ in the XK group $(\mathrm{p}<0.05-0.01)$ and at $30-120 \mathrm{~min}$ in the XTZ group $(p<0.05-0.01)$. No change in the heart rate was observed following $\mathrm{TZ}$ administration. The lowest values of heart rate were for the XTZ group at the $120^{\text {th }}$ minute and in the XK group at the $75^{\text {th }}$ minute (Tab. 2).

The respiratory rate decreased compared to the baseline values in all the anaesthetized groups. Compared to the baseline values, the respiratory rate was decreased at 5-120 min in the KX and XTZ groups $(\mathrm{p}<0.05-0.01)$ and at $15-60 \mathrm{~min}$ in the TZ group $(\mathrm{p}<0.05-0.01)$. The lowest values of respiratory rate were at $60 \mathrm{~min}(93.75$ $\pm 2.39)$ in the $\mathrm{TZ}$ group, $30 \mathrm{~min}(57.00 \pm 1.22)$ in the $\mathrm{XK}$ group, and 45 and $60 \mathrm{~min}(48.00 \pm 2.70)$ in the XTZ group (Tab. 2).

Values for the body temperature of the rabbits are given in Tab. 3. Compared to the baseline values, the body temperature decreased at 30-120 min in the KX group ( $\mathrm{p}<0.05-0.01$ ), and at 45-120 $\mathrm{min}$ in the XTZ group $(\mathrm{p}<0.05-0.01)$. In all the groups, the lowest body temperature values were recorded at the $90^{\text {th }}$ minute (Tab. 3).

There was no statistically significant difference in the hematological parameters during anesthesia among the anesthesia groups $(\mathrm{p}>0.05)$. Biochemical parameters of the rabbits are given in Tab. 4. Serum AST levels increased during anesthesia in the XTZ group compared to that in the XK group. On the first day after anesthesia induction, the ALP levels increased more in the XTZ group than in the TZ group. However, the increases in the AST and ALP levels were determined to be within the reference values (15). Serum BUN and urea levels in the XTZ group significantly increased after anesthesia induction compared to that before anesthesia induction. Moreover, there was a significant
Tab. 3. Body temperature at various times in the xylazine-ketamine (XK), xylazine-tiletamine-zolazepam (XTZ), and tiletamine-zolazepam (TZ) groups $(\bar{x} \pm S D, n=6)$

\begin{tabular}{|r|c|c|c|}
\hline $\begin{array}{r}\text { Time } \\
(\mathrm{min})\end{array}$ & $\mathrm{3}$ & $\mathrm{3}$ & $\mathrm{X}$ \\
\hline 0 & $38.43 \pm 0.23$ & $38.77 \pm 0.18$ & $38.40 \pm 0.24$ \\
\hline 5 & $38.10 \pm 0.16$ & $38.70 \pm 0.25$ & $38.47 \pm 0.14$ \\
15 & $38.05 \pm 0.35$ & $38.50 \pm 0.28$ & $38.05 \pm 0.17$ \\
\hline 30 & $37.20 \pm 0.07^{* *}$ & $38.02 \pm 0.19^{* *}$ & $37.15 \pm 0.42$ \\
\hline 45 & $36.95 \pm 0.10^{* *}$ & $37.80 \pm 0.15^{* *}$ & $36.87 \pm 0.38^{*}$ \\
60 & $37.00 \pm 0.20^{* *}$ & $37.40 \pm 0.09^{* *}$ & $36.32 \pm 0.27^{*}$ \\
\hline 75 & $36.85 \pm 0.18^{* *}$ & $36.90 \pm 0.07^{* *}$ & $36.45 \pm 0.23^{*}$ \\
\hline 90 & $36.83 \pm 0.11^{* *}$ & $36.58 \pm 0.10^{* *}$ & $36.55 \pm 0.21^{* *}$ \\
120 & $37.00 \pm 0.24^{* *}$ & $36.90 \pm 0.26^{* *}$ & $36.68 \pm 0.24^{* *}$ \\
\hline
\end{tabular}

Explanation: statistical significance at each time point according to baseline values in all groups: $* \mathrm{p}<0.05 ; * \mathrm{p}<0.01$

increase in the serum BUN in the XTZ group compared to that in the $\mathrm{XK}$ and $\mathrm{TZ}$ groups after anesthesia was administered $(\mathrm{p}<0.05)$.

In this study, anesthesia evaluation was performed based on reflex examinations without any surgical intervention. The mean induction times in rabbits vary between 2.5 and $4.6 \mathrm{~min}$ subsequent to the injection of $\mathrm{XK}, \mathrm{TZ}$, and XTZ combinations at different doses $(1,8$, $16,22,25)$. The duration of anesthesia was reported to be 67.7 minutes for rabbits administered TZ (8), 61.4$-109.5 \mathrm{~min}$. for those administered XK $(1,22,25)$, and 104.6-125.5 min for those given XTZ $(2,8,25)$. In the present study, induction was achieved most quickly in the XTZ group $(2.71 \pm 0.81 \mathrm{~min})$, followed by that in the TZ $(2.96 \pm 1.36 \mathrm{~min})$ and XK groups $(3.03 \pm 1.05$ $\min )(p>0.05)$. After the evaluation of the total duration of anesthesia, the longest anesthesia duration was for the XTZ group $(115.50 \pm 9.26 \mathrm{~min})$ followed by that for the XK $(80.35 \pm 10.41 \mathrm{~min})$ and TZ groups (61.15 $\pm 6.95 \mathrm{~min})(\mathrm{p}<0.001)$ (Tab. 1). The findings of the present study are consistent with previous reports (1, $2,8,16,22,25)$. 
Tab. 4. The mean ( \pm SD) serum ALT, AST, ALP, bilirubin, BUN and urea concentrations at various times in the xylazine-ketamine (XK), xylazine-tiletamine-zolazepam (XTZ), and tiletamine-zolazepam (TZ) groups ( \pm SD)

\begin{tabular}{|c|c|c|c|c|c|c|}
\hline \multirow{2}{*}{ Parameters } & \multirow{2}{*}{$\begin{array}{l}\text { Groups } \\
(n=6)\end{array}$} & \multirow{2}{*}{$\begin{array}{l}\text { Before anesthesia } \\
\qquad(0 \mathrm{~min})\end{array}$} & \multirow{2}{*}{$\begin{array}{l}\text { During anesthesia } \\
\text { (60 min) }\end{array}$} & \multicolumn{3}{|c|}{ After anesthesia } \\
\hline & & & & $1^{\text {st }}$ day & $3^{\text {rd day }}$ & $5^{\text {th }}$ day \\
\hline \multirow[t]{3}{*}{ ALT (IU/I) } & XK & $26.75 \pm 4.68$ & $36.00 \pm 13.74$ & $39.50 \pm 6.71$ & $27.75 \pm 2.72$ & $26.25 \pm 2.78$ \\
\hline & XTZ & $27.12 \pm 2.95$ & $23.50 \pm 9.30$ & $37.25 \pm 9.99$ & $30.00 \pm 3.19$ & $30.75 \pm 2.25$ \\
\hline & TZ & $27.25 \pm 1.49$ & $34.65 \pm 4.90$ & $38.50 \pm 8.66$ & $33.75 \pm 7.82$ & $31.75 \pm 4.75$ \\
\hline \multirow[t]{3}{*}{ AST (IU/I) } & XK & $14.25 \pm 5.40^{\mathrm{a}}$ & $12.50 \pm 2.63^{\mathrm{a}}$ & $11.00 \pm 1.58^{\mathrm{a}}$ & $8.50 \pm 0.96^{a}$ & $8.50 \pm 1.44^{\mathrm{a}}$ \\
\hline & XTZ & $16.25 \pm 0.85^{a b}$ & $19.75 \pm 0.63^{b}$ & $22.25 \pm 2.89^{b}$ & $19.75 \pm 3.50^{b}$ & $18.25 \pm 1.65^{b}$ \\
\hline & TZ & $16.50 \pm 4.74^{\mathrm{ab}}$ & $14.75 \pm 4.33^{\mathrm{ab}}$ & $13.50 \pm 6.10^{a b}$ & $10.75 \pm 3.79^{\mathrm{ab}}$ & $10.50 \pm 2.43^{\mathrm{ab}}$ \\
\hline \multirow[t]{3}{*}{ ALP (IU/I) } & XK & $85.75 \pm 15.32$ & $83.25 \pm 10.82$ & $99.25 \pm 15.48^{\mathrm{ab}}$ & $115.50 \pm 16.38$ & $84.25 \pm 18.79$ \\
\hline & XTZ & $91.00 \pm 12.73^{a}$ & $86.50 \pm 4.52^{\mathrm{a}}$ & $122.75 \pm 10.41^{a}$ & $119.00 \pm 22.90^{a}$ & $101.50 \pm 22.41^{a}$ \\
\hline & TZ & $87.25 \pm 11.88$ & $72.50 \pm 6.64$ & $86.75 \pm 8.25^{b}$ & $99.25 \pm 10.78$ & $102.00 \pm 5.20$ \\
\hline \multirow[t]{3}{*}{ Bilirubin (mg/dl) } & XK & $0.04 \pm 0.03$ & $0.12 \pm 0.09$ & $0.05 \pm 0.01$ & $0.12 \pm 0.04$ & $0.11 \pm 0.04$ \\
\hline & XTZ & $0.08 \pm 0.04$ & $0.19 \pm 0.02$ & $0.11 \pm 0.04$ & $0.13 \pm 0.04$ & $0.15 \pm 0.02$ \\
\hline & TZ & $0.07 \pm 0.02$ & $0.17 \pm 0.02$ & $0.04 \pm 0.01$ & $0.07 \pm 0.04$ & $0.11 \pm 0.02$ \\
\hline \multirow[t]{3}{*}{ BUN (mg/dl) } & XK & $11.50 \pm 0.65^{\mathrm{a}}$ & $14.25 \pm 1.25^{\mathrm{a}}$ & $16.75 \pm 1.37^{\mathrm{a}}$ & $16.25 \pm 2.01^{a}$ & $12.75 \pm 1.03^{\mathrm{a}}$ \\
\hline & XTZ & $16.00 \pm 1.68^{\mathrm{a}}$ & $17.50 \pm 1.66^{\mathrm{a}}$ & $48.75 \pm 7.97^{b}$ & $33.50 \pm 6.62^{b}$ & $27.25 \pm 2.49^{b}$ \\
\hline & TZ & $14.75 \pm 1.65^{\mathrm{a}}$ & $15.00 \pm 2.27^{\mathrm{a}}$ & $11.50 \pm 1.04^{\mathrm{a}}$ & $11.00 \pm 0.40^{a}$ & $12.25 \pm 1.49^{\mathrm{a}}$ \\
\hline \multirow[t]{3}{*}{ Urea (mg/dl) } & XK & $25.65 \pm 1.37^{\mathrm{a}}$ & $31.35 \pm 1.55^{\mathrm{a}}$ & $40.70 \pm 6.50^{\mathrm{a}}$ & $37.95 \pm 3.95^{\mathrm{a}}$ & $28.05 \pm 2.27^{\mathrm{a}}$ \\
\hline & XTZ & $35.20 \pm 3.70^{\mathrm{a}}$ & $38.50 \pm 3.65^{\mathrm{a}}$ & $107.25 \pm 17.54^{b}$ & $66.75 \pm 11.55^{b}$ & $57.10 \pm 5.95^{\mathrm{b}}$ \\
\hline & TZ & $32.45 \pm 3.63^{\mathrm{a}}$ & $33.00 \pm 5.00^{\mathrm{a}}$ & $25.30 \pm 2.29^{\mathrm{a}}$ & $24.20 \pm 0.90^{a}$ & $26.95 \pm 3.28^{\mathrm{a}}$ \\
\hline
\end{tabular}

Explanations: a, b, c - means with different superscript letters differ significantly in the same row at $\mathrm{p}<0.05$; statistical significance between different letters in the same column for different groups: $\mathrm{p}<0.05$

The surgical anesthesia duration starts with the disappearance of the ear and pedal withdrawal reflexes and ends with the return of these reflexes (33). It was reported that ear pinch and pedal withdrawal reflexes disappeared, and surgical anesthesia was performed in rabbits anesthetized with the XK $(4 \mathrm{mg} / \mathrm{kg}+50$ $\mathrm{mg} / \mathrm{kg})$ and XTZ $(3 \mathrm{mg} / \mathrm{kg}+30 \mathrm{mg} / \mathrm{kg})$ combinations (17). Studies have reported that reflexes do not disappear in rabbits anesthetized with $20 \mathrm{mg} / \mathrm{kg} \mathrm{TZ}$ (8) or in those given $32 \mathrm{mg} / \mathrm{kg}$ and $64 \mathrm{mg} / \mathrm{kg}$ TX (2); therefore, no surgical anesthesia occurred. In the present study, the disappearance time of ear and pedal withdrawal reflexes was longer in the XTZ group than in the XK group $(p<0.001)$ (Tab. 1). Surgical anesthesia and analgesia with adequate muscle relaxation were believed to have been achieved in the XK and XTZ groups. Furthermore, the fact that the duration of anesthesia in the XTZ group was longer than that in the XK group confirmed that tiletamine is 2-3 times more effective as an anesthetic agent than ketamine (20). Further, the reflexes did not disappear during the anesthesia induction; therefore, sufficient muscle relaxation and analgesia were not achieved in the TZ group (Tab. 1). This finding regarding the $\mathrm{TZ}$ group was consistent with previous reports according to which $\mathrm{TZ}$ produces a superficial anesthesia effect in rabbits and is unsuitable for painful surgical manipulations (8). In rats, it is recommended that $\mathrm{TZ}$ be used in combination with an alpha-2 adrenoceptor agonist, such as xylazine, or an analgesic, such as butorphanol, to produce an appropriate analgesic effect necessary for surgical procedures (31). Consistent with the findings of Wilson et al. (31), the present study showed that the use of TZ in combination with an alpha-2 adrenoreceptor agonist, such as xylazine, could be appropriate for achieving adequate analgesia in rabbits.

It has been reported that in rabbits anesthetized with different doses of XK, $(3 \mathrm{mg} / \mathrm{kg}+10 \mathrm{mg} / \mathrm{kg}$ intravenous [IV]) $(10,11),(4 \mathrm{mg} / \mathrm{kg}+50 \mathrm{mg} / \mathrm{kg}$ intramuscular [IM]) (17), (10 mg/kg + 50 mg/kg [IM]) (33), and $(5 \mathrm{mg} / \mathrm{kg}+35 \mathrm{mg} / \mathrm{kg}$ [IM]) (25), both the respiratory rate and heart rate decreased and that XK anesthesia caused respiratory depression, bradycardia, and hypotension $(10,11,17,25,33)$. In a study on rabbits, the XK combination $(5 \mathrm{mg} / \mathrm{kg}+50 \mathrm{mg} / \mathrm{kg})$ reduced the respiratory rate without a significant change in the heart rate compared to the pre-anesthetic values (16). In another study, a combination of XK $(5 \mathrm{mg} / \mathrm{kg}+35$ $\mathrm{mg} / \mathrm{kg}$ ) increased the respiratory rate, while it exerted no significant effect on the heart rate. The increased respiratory rate was attributed to the anesthesia attempt and to the increasing oxygen demand of the rabbit in during the anesthesia (22). In the present study, it was determined that due to XK $(5 \mathrm{mg} / \mathrm{kg}+50 \mathrm{mg} / \mathrm{kg}) \mathrm{IM}$ administration the respiratory rate and the heart rate started to decrease in comparison to baseline values, in the following $5^{\text {th }}$ and $15^{\text {th }}$ minutes, respectively, and continued to decrease during the anesthesia (Tab. 2). 
The results of the present study are consistent with the majority of previous reports on this subject (10, $11,17,25,33)$, and we hypothesize that the decrease in heart rate resulted from the decreased sympathetic activity and increased vagal activity due to xylazine (12), while the decrease in respiratory rate was due to both the moderate respiratory depressive effects of ketamine (29) and xylazine-induced vasoconstriction or slowed pulmonary blood flow (12).

It was stated that in rabbits the XTZ combination $(5 \mathrm{mg} / \mathrm{kg}+15 \mathrm{mg} / \mathrm{kg})$ decreased the respiratory rate after atropine premedication; however, the reduction was not significant, and there was no significant change in the heart rate compared to the pre-anesthesia values (16). Another study reported that rabbits anesthetized with the same dose of XTZ combination developed cardiovascular and respiratory depression, and the respiratory rate was decreased (25). Moreover, the XTZ combination reportedly causes hypotension, bradycardia, and respiratory depression in rats (32). The potential underlying cause of these effects was believed to be the depressive effect of xylazine on the heart and arterial blood pressure, and the combination, via the addition of xylazine to the $\mathrm{TZ}$ combination, exerted a strong cardiovascular depressant effect $(25,32)$. The present study established that the XTZ combination $(5 \mathrm{mg} / \mathrm{kg}+15 \mathrm{mg} / \mathrm{kg})$ significantly reduced both the heart rate and respiratory rate in rabbits (Tab. 2). Such an effect of XTZ was also reported in several preceding studies $(25,32)$; however, the present results displayed dissimilarities with other studies (16). This could be because xylazine combined with $\mathrm{TZ}$ probably induced a dominant effect on the sympathetic stimulus effect (14) of tiletamine.

A $15 \%$ decrease in the heart rate compared to the pre-anesthesia rate was reported in rats administered a high dose of TZ (32 mg/kg and $64 \mathrm{mg} / \mathrm{kg})$ for both doses; this reduction could be explained by the negative chronotropic effect of $\mathrm{TZ}$ on the cardiovascular system (2). It was stated that a superficial anesthesia was formed in anesthetized rabbits with TZ $(20 \mathrm{mg} /$ $\mathrm{kg}$ ), the heart rate was increased, and this increase was induced both by the sympathetic stimulation effect of tiletamine and the minimal cardiovascular effect of zolazepam. It was also reported that the increase in heart rate could be related to the superficial anesthesia (8). Further, the heart rate was slightly affected and hypertension, a cardio-stimulant effect of dissociative anesthetics, was observed in rats anesthetized with TZ (32); there were minimal changes in the respiratory rate (5). In another study on rabbits, the heart rate and respiratory rate were significantly altered compared to the baseline value after TZ administration (27). In the present study, the heart rate remained unaltered from the control values, and there was a short-term reduction in the respiratory rate of rabbits given TZ $(15 \mathrm{mg} / \mathrm{kg})$ (Tab. 2). This indicated that the lack of change in the heart rate was due to the tiletamine-stimulated sympathetic activity (14) and that the short-term decrease in the respiratory rate was due to the moderate effect of tiletamine (29) and the minimal effect of zolazepam on the respiratory system.

In a study that focused on the anesthetic effects of XK and XTZ combinations in rabbits, both combinations caused respiratory depression; however, the depressive effect of the XTZ combination was significantly higher than that of XK, and the excessive depressive activity was induced by xylazine (25). It was indicated that the heart rate in rabbits anesthetized with $\mathrm{TZ}(20 \mathrm{mg} / \mathrm{kg})$ and XTZ $(3 \mathrm{mg} / \mathrm{kg}+20 \mathrm{mg} / \mathrm{kg})$ was significantly higher in the TZ group. Xylazine reportedly decreased the respiratory and heart rates and arterial blood pressure in the XTZ group due to its depressive effect on the respiratory and cardiovascular system (8). In the present study, the most severe depressive effect on the heart rate and respiratory rate was induced by the XTZ combination, followed by that exerted by the XK combination (Tab. 2). The TZ combination had no depressive effect on the heart rate and caused a short depressive effect on the respiratory rate.

Several studies have reported no significant changes in the body temperatures of the rabbits anesthetized with XK (10), XTZ (16), and TZ (27) in comparison to the pre-anesthetic values. In addition, another study indicated that, owing to the administration of alpha-2 adrenoceptor agonists, the rectal temperature dropped due to thermoregulatory control loss after injection (27). In the present study, the body temperatures started to decrease after the $30^{\text {th }}$ to $45^{\text {th }}$ minutes of administration for all combinations and remained lower than the control values until the end of the anesthesia effect (Tab. 3). We hypothesize that this decrease in body temperature is due to the fact that anesthetic agents cause the thermoregulatory center to depress (18) and the animal remains immobilized during the anesthesia $(24,26)$. We think that the depressive effect of xylazine on the CNS (26) and the hypothermic effect of animals with a small surface area of TZ (24) are also effective in decreasing body temperature in rabbits.

A previous trial reported no significant change in the hematological parameters of rabbits anesthetized with a high dose of TZ (32 mg/kg and $64 \mathrm{mg} / \mathrm{kg})(2)$. XK $(3 \mathrm{mg} / \mathrm{kg}+10 \mathrm{mg} / \mathrm{kg}$ [IV]) reportedly had no significant effect on the hematological parameters of rabbits (10). Moreover, the XTZ combination had no significant effect on the hematological parameters of gazelles (34). Xylazine has also been reported to have no effect on the whole blood values of pigs (4). In keeping with these reports, the present study also showed that none of the combinations caused significant changes in the hematological parameters of rabbits $(2,4,10,34)$.

It was reported that the XK combination increases the levels of ALT, AST, and BUN in rabbits; however, these values return to normal after 24 hours, and vari- 
ous anesthetic agents are reported to affect the serum enzyme and biochemical parameters $(9,10)$. XK is believed to increase the serum AST/ALT concentration in laboratory animals without causing any histopathological disease in the liver and the peritoneum. The potential cause for these increases was believed to the damage to the muscle tissue during the injection of the anesthetic material (30). Although plasma AST, ALP, and ALT concentrations were increased in rabbits anesthetized using XK $(3 \mathrm{mg} / \mathrm{kg}+10 \mathrm{mg} / \mathrm{kg}$ $[\mathrm{IV}])$, this increase was reportedly normal for these species. The same study indicated that plasma BUN and creatinine concentrations increased until the $120^{\text {th }}$ minute of anesthesia induction $(10,11)$. In the present study, the XTZ group exhibited greater increases in the serum AST concentration than the XK group, and the serum ALP concentration increased more than in the TZ group. However, these increases were insignificant for the intra-group statistical evaluations (Tab. 4) and were within the reference value range (15). Furthermore, the serum enzyme activities should increase approximately 3 times that of the baseline values for diagnostic significance (28). Therefore, such increases were diagnostically insignificant and could be interpreted as the reflection of minimal metabolic effects of the anesthetic agents.

In a study that investigated the nephrotoxic effects of tiletamine and zolazepam, tiletamine, at a dose of $32 \mathrm{mg} / \mathrm{kg}$, increased the serum BUN and creatinine levels; renal tubular necrosis was determined histopathologically. However, $7.5 \mathrm{mg} / \mathrm{kg}$ tiletamine administration only caused mild nephrosis, identified histopathologically (6). In rabbits anesthetized with various doses of TZ ( $32 \mathrm{mg} / \mathrm{kg}$ and $64 \mathrm{mg} / \mathrm{kg})$, those administered high doses had abnormal post-anesthesia increases in the serum BUN and creatinine levels until the $6^{\text {th }}$ day and had diffuse nephrosis in the kidneys histopathologically; those administered low doses had multifocal nephrosis, and tiletamine was identified as a potential cause for the nephrotoxic formation in rabbits (2). In the present study, no significant changes in the post-anesthesia serum creatinine and BUN concentrations were observed in rabbits anesthetized with the TZ combination until the $5^{\text {th }}$ day (Tab. 4). Hence, both low doses of TZ (15 mg/kg) and increased glomerular filtration rate and blood flow in the kidneys (21) induced by hypertension because of the cardiovascular stimulant effect of tiletamine $(5,32)$ possibly prevented the potential nephrotoxic effect of TZ, given that high doses of TZ $(32 \mathrm{mg} / \mathrm{kg}$ and $64 \mathrm{mg} / \mathrm{kg}$ ) are known to exert nephrotoxic effects $(2,6)$. Effective surgical anesthesia was achieved in rabbits administered xylazine $(5 \mathrm{mg} / \mathrm{kg})$ and TZ $(15 \mathrm{mg} / \mathrm{kg})$, and no significant nephrotoxic effect following 7 days after injection was reported for the serum creatinine and BUN levels (25). In the present study, significant increases were observed for the serum creatinine and
BUN concentrations compared to the pre-anesthesia values and compared to that in the $\mathrm{TZ}$ and $\mathrm{XK}$ groups in rabbits anesthetized with the same dose of XTZ $(5 \mathrm{mg} / \mathrm{kg}$ xylazine and $15 \mathrm{mg} / \mathrm{kg} \mathrm{TZ})$ until the $5^{\text {th }}$ post-anesthetic day (Tab. 4). Therefore, we can conclude that xylazine added to $\mathrm{TZ}$ could be associated with a possible increase in the nephrotoxic effects of TZ, as reported by several researchers $(2,6)$, causing hypotension, reducing cardiac output $(4,29)$, and reducing the glomerular filtration rate and blood flow in the kidneys (21).

Thus, although XK reduced the heart rate and respiration rate in rabbits, $\mathrm{XK}$ can be recommended as an anesthetic combination in rabbits owing to its adequate analgesic effect and the surgical anesthesia duration. The TZ combination is advisable only in painless surgical manipulations in rabbits because it does not provide adequate analgesic effect, muscle relaxation, and surgical anesthesia duration. Although the XTZ combination provided adequate analgesia, muscle relaxation, and surgical anesthesia duration in rabbits, it was found to exert a nephrotoxic effect due to the increased serum creatinine and BUN concentrations; thus it was not considered as an appropriate combination of anesthesia for renal invasive procedures and/ or experimental nephrotoxicity studies.

\section{References}

1. Adetunji A., Lawal F. M., Oguntoye C. O.: Responses of rabbits to concurrent administration of Furosemide and Xylazine-Ketamine. Nigerian Vet. J. 2013, 34, 863-869.

2.Brammer D. W., Doerning B. J., Chrisp C. E., Rush H. G.: Anesthetic and nephrotoxic effects of Telazol in New Zealand white rabbits. Lab. Anim. Sci. 1991, 41, 432-435.

3. Brodbelt D.: Perioperative mortality in small animal anaesthesia. Vet. J. 2009, $182,152-161$.

4. Cepiel A., Noszczyk-Nowak A., Janiszewski A., Pasławski R., Pasławska U. Effect of xylazine, medetomidine and dexmedetomidine on cardiac conduction in pigs. Med. Weter. 2018, 74, 187-192.

5. Chen L., Yin Y. P., Wu C. C., Jiang S., Fan H. G., Lu D. Z.: Anesthesia with intraperitoneal tiletamine/zolazepam, xylazine, and tramadol in mice. Med. Weter. 2015, 71, 219-223.

6. Doerning B. J., Brammer D. W., Chrisp C. E., Rush H. G.: Nephrotoxicity of tiletamine in New Zealand white rabbits. Lab. Anim Sci. 1992, 42, 267-269.

7. Doherty T. J.: Physiologic effects of alpha 2-adrenergic receptors. J. Am. Vet. Med. Assoc. 1988, 192, 1612-1614.

8. Dupras J., Vachon P., Cuvelliez S., Blais D.: Anesthesie du lapin de Nouvelle-Zelande utilisant les combinaisons tiletamine-zolazepam et ketaminemidazolam avec ou sans xylazine. Can. Vet. J. 2001, 42, 455-460.

9. Gil A. G., Silvan G., Illera M., Illera J. C.: The effects of anesthesia on the clinical chemistry of New Zealand white rabbits. Contemp. Top. Lab. Anim. Sci. 2004, 43, 25-29.

10. Gonzalez G. A., Illera J. C., Silvan G., Illera M.: Effects of the anaesthetic/ tranquillizer treatments on selected plasma biochemical parameters in NZW rabbits. Lab. Anim. 2003, 37, 155-161

11. Gonzalez G. A., Illera J. C., Silvan G., Lorenzo P. L., Illera M.: Changes in hepatic and renal enzyme concentrations and heart and respiratory rates in New Zealand white rabbits after anesthetic treatments. Contemp. Top. Lab. Anim. Sci. 2002, 41, 30-32.

12. Greene S. A., Thurmon J. C.: Xylazine - a review of its pharmacology and use in veterinary medicine. J. Vet. Pharmacol. Ther. 1988, 11, 295-313.

13. Grint N. J., Murison P. J.: A comparison of ketamine-midazolam and ketamine-medetomidine combinations for induction of anaesthesia in rabbits. Vet. Anaesth. Analg. 2008, 35, 113-121.

14. Hellyer P., Muir W., Hubbell J., Sally J.: Cardiorespiratory effects of the intravenous administration of tiletamine-zolazepam to cats. Vet. Surg. 1988, $17,105-110$ 
15. Hewitt C. D., Innes D. J., Savory J., Wills M. R.: Normal biochemical and hematological values in New Zealand white rabbits. Clin. Chem. 1989, 35, 1777-1779.

16. Kaya U., Apaydın N., Kaya A., Koc B.: Comparision of cardiovascular and respiratorik effects xtlazine-tiletamine-zolazepam and xylazine-ketamine anesthesia in rabbits. Vet. Cer. Derg. 2002, 8, 63-68.

17. Kılıç N.: A comparison between medetomidine-ketamine and xylazine-ketamine anaesthesia in rabbits. Turk J. Vet. Anim. Sci. 2004, 28, 921-926.

18. Kolata R. J.: Monitoring the surgical patient, [in:] Slatter D. (ed.): Textbook of Small Animal Surgery, W. B. Saunders Company, Philadelphia 1993, p. $213-$ -214 .

19. Kumar A., Mann H. J., Remmel R. P.: Determination of constituents of Telazol-tiletamine and zolazepam by a gas chromatography/mass spectrometry-based method. J. Chromatogr. B. 2006, 2, 131-135.

20. Lester P. A., Moore R. M., Shuster K. A., Myers D. D.: Anesthesia and analgesia [in:] Mark A., Suckow M. A., Stevens K. A., Wilson R. P. (ed.): The Laboratory Rabbit, Guinea pig, Hamster, and other Rodents. Elsevier, $1^{\text {st }}$ Edition, 2012 p. 33-56.

21. Mercatello A.: Changes in renal function induced by anesthesia. Ann. Fr. Anesth. Reanim. 1990, 9, 507-524.

22. Oguntoye C. O., Oke B. O.: A Comparison of xylazine/ketamine, diazepam/ ketamine and acepromazine/ketamine anaesthesia in Rabbit. Sokoto J. Vet. Sci. 2014, 12, 21-25.

23. Peeters M. E., Gil D., Teske E., Eyzenbach V., vd Brom W. E., Lumeij J. T., de Vries $H$. W. Four methods for general anaesthesia in the rabbit: a comparative study. Lab. Anim. 1988, 22, 355-360.

24. Plumb D. C.: Plumb's Veterinary Drug Handbook, Pharma.Vet. Inc., Stockholm 2008, p. 882-883.

25. Popilskis S. J., Oz M. C., Gorman P., Florestal A., Kohn D. F.: Comparison of xylazine with tiletamine-zolazepam (Telazol) and xylazine-ketamine anesthesia in rabbits. Lab. Anim. Sci. 1991, 41, 51-53.
26. Posner L. P., Burns P.: Sedative agents: tranquilizers alpha-2 agonists and related agents, [in:] Riviere J. E., Papich M. G. (ed.): Veterinary Pharmacology and Therapeutics. Wiley-Blackwell, Ames, Iowa 2009, p. 337-380.

27. Tannus L. F., Eurides D., Guimaraes E. C., de Souza L. A., de Souza R. R. Renal hematological and biochemical evaluation on rabbits under anesthesia at the yintang acupoint with tiletamine and zolazepam. Arq. Ciênc. Vet. Zool. 2013, 16, 149-153.

28. Turgut K.: Veteriner klinik laboratuvar teşhis, Bahçıvanlar Basım Sanayi AŞ., Konya, p. 203-257.

29. Vogler G. A.: Anesthesia and analgesia, [in:] Suckow M. A., Weisbroth S. H., Franklin C. L. (ed.): The Laboratory Rat. Elsevier Academic Press, $2^{\text {nd }}$ Edition, 2006, p. 627-664.

30. Wellington D., Mikaelian I., Singer L.: Comparison of ketamine-xylazine and ketamine-dexmedetomidine anesthesia and intraperitoneal tolerance in rats. JAALAS 2013, 52, 481-487.

31. Wilson R. P., Zagon I. S., Larach D. R., Lang C. M.: Antinociceptive properties of tlletamine-zolazepam improved by addition of xylazine or butorphanol. Pharmacol. Biochem. Behav. 1992, 43, 1129-1133.

32. Wilson R. P., Zagon I. S., Larach D. R., Lang C. M.: Cardiovascular and respiratory effects of tiletamine-zolazepam. Pharmacol. Biochem. Behav. 1993, 44, 1-8.

33. Yanmaz L., Doğan E., Okumuş Z., Şenocak M., Yıldırım F.: Xylazine-ketamine anesthesia following premedication of New Zealand white rabbits with vitamin C. Kafkas Univ. Vet. Fak. Derg. 2016, 22, 115-118.

34. Yaralioglu-Gurgoze S., SindakN., Sahin T., Cen O.: Levels of glutathione peroxidase, lipoperoxidase and some biochemical and haematological parameters in gazelles anaesthetised with a tiletamin-zolazepam-xylazine combination. Vet. J. 2005, 169, 126-128.

Corresponding author: Asist. Prof. Dr. Abdullah Karasu, Faculty of Veterinary Medicine, University of Van Yuzuncu Yil, Campus, 65080 Van, Turkey; e-mail: abdullahkarasu@hotmail.com 